\title{
The neurological manifestations of the acute porphyrias
}

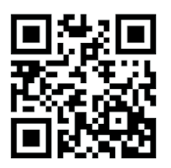

The porphyrias are a group of eight metabolic disorders, each of which is associated with a specific enzymatic alteration in the haem biosynthetic pathway. ${ }^{[1]}$ In general, the porphyrias share one or both of two clinical symptom complexes: cutaneous photosensitivity, which results from the interaction of light and photoactive porphyrin molecules in the skin; and the acute attack, a serious complication associated with a phase of accelerated hepatic porphyrin synthesis. The acute attack is a feature of four porphyrias: acute intermittent porphyria (AIP); variegate porphyria; hereditary coproporphyria; and aminolaevulinic acid (ALA) dehydratase porphyria. All four are so-called 'hepatic' porphyrias, in which the haem synthetic defect is expressed in non-erythroid cells, notably hepatocytes.

The acute attack is a potentially severe illness that may result in severe debilitation and death. The clinical features are metabolic, principally hyponatraemia, and neurological, related to autonomic, motor and cerebral dysfunction. ${ }^{[2-4]}$ Autonomic dysfunction is associated with a characteristic diffuse, severe and poorly localised abdominal pain, sympathetic over-activity manifesting as tachycardia, hypertension or a labile blood pressure and cardiac arrhythmias, and gastrointestinal dysfunction causing nausea, vomiting and ileus.

Cerebral dysfunction may present as seizures, transient cerebral ischaemia, posterior reversible encephalopathy syndrome (PRES) or coma. ${ }^{[5]}$ Seizures may be precipitated by hyponatraemia, cerebral ischaemia and the administration of epileptogenic medication, such as pethidine (meperidine) prescribed for pain relief. ${ }^{[6]}$ Hyponatraemia may result from the syndrome of inappropriate antidiuretic hormone secretion (SIADH), renal tubular dysfunction and the administration of hypotonic intravenous fluids such as dextrose. ${ }^{[7]}$ Rarely, brainstem dysfunction may occur in response to transient ischaemia or hyponatraemia, ${ }^{[8]}$ as may cerebral infarction. ${ }^{[9]}$ Acute psychotic states are occasionally observed. ${ }^{[10]}$ All these alarming features, other than the pain, nausea and cardiovascular effects, are seen in a minority of cases, and usually accompany a particularly severe and often unrecognised, untreated acute attack.

A more common manifestation of more severe attacks is a sudden-onset, predominantly motor, peripheral neuropathy. The typical presentation is of a rapid onset of muscle weakness following a prodrome of 1 - 2 days of abdominal pain and other symptoms of the acute attack. Sensory symptoms are never prominent. Muscle weakness is symmetrical and evenly distributed in the proximal and distal muscle groups of the upper limbs, although it may typically start proximally, particularly in the legs. ${ }^{[1]}$ In our experience, it is not infrequently misdiagnosed as Guillain-Barré syndrome. Progressive weakness can progress to respiratory failure. Cranial nerve involvement may occur. Before the introduction of modern techniques of assisted ventilation, such attacks were fatal. Quadriparesis is reversible, but may require prolonged ventilatory support and many months of rehabilitation. Occasionally patients present with atypical neurological manifestations. Single cases of mononeuritis multiplex ${ }^{[12]}$ and 'pseudomyasthenia' during an acute attack have been described. Patients with pre-existing neuropathy who experience recurrent attacks may demonstrate a transient decrease in muscle strength with a return to baseline following cessation of the attack. ${ }^{[13]}$

Nerve conduction studies and pathological examination typically indicate a pattern of axonal necrosis rather than demyelination. ${ }^{[3]}$ The pathogenesis is poorly understood. A direct, toxic effect of the porphyrin precursors, particularly ALA, on neuronal tissue has been postulated. Interestingly, the chemical structure of ALA closely resembles that of $\gamma$-aminobutyric acid (GABA), a known neurotransmitter. ${ }^{[13]} \mathrm{A}$ contrasting hypothesis is that porphyria-associated impaired haem synthesis results in intraneuronal haem deficiency, with consequent intracellular energy depletion and dysfunction. ${ }^{[14]}$ This view has become less tenable since repeated experience with liver transplantation has shown that this effectively removes the potential for future acute attacks 
in patients subject to frequent and debilitating recurrent attacks, ${ }^{[15]}$ even though haem biosynthesis in all non-erythroid cells, including neurons (with the exception of the engrafted hepatocytes), continue to operate in a haem-deficient environment.

The symptomatic patient with an acute, severe porphyria therefore typically presents with a sudden onset of a characteristic syndrome of acute abdominal pain, accompanied by other clinical features as described above, which may then progress to a sudden onset of quadriparesis over the course of a few hours. Recovery thereafter may be prolonged. The unfortunate patient may have further acute attacks following the same pattern.

In this issue of the SAMJ, an atypical neurological presentation of AIP in a young man is described. ${ }^{[16]}$ Two points are of particular interest. Firstly, although the observed pattern of neurological dysfunction was quite compatible with an acute porphyria, the expected history of an abrupt onset preceded by a short prodrome of typical porphyric symptoms was completely absent. There were no preceding symptoms suggestive of an acute attack, and weakness developed cumulatively over a prolonged period. It is not surprising that a condition such as motor neuron disease featured prominently in the initial differential diagnosis. The patient was fortunate in that, certain inconsistent features having been recognised, he was referred to a neurology unit where exclusion of porphyria is a standard practice for patients with unexplained neuropathy, given the very high prevalence of porphyria in the South African population. ${ }^{[17]}$ The second point of interest is the rapid improvement in neurological function in response to definitive therapy for porphyria with haem arginate. Given that the predominant underlying pathological state is one of severe axonal necrosis, rapid improvement is not expected. Yet, in this case treatment was followed by a prompt, though partial, improvement. That it was incomplete is easily explained given that neurophysiological studies did indeed confirm the presence of axonal necrosis. It does, however, support the suggestion that, in at least some cases, motor neuron function is transiently depressed under circumstances of haem depletion, with the potential for rapid improvement when this is corrected. ${ }^{[6]}$

Two conclusions may be drawn from this report. For the clinician it is a reminder that acute forms of porphyria should never be forgotten when confronted with a patient with unexplained motor neuropathy, whether or not the characteristic features of the acute attack are present. For those with a research interest in neuropathophysiology, it is an invitation: an interesting, fruitful and under-explored field - the interplay of disordered haem synthesis and neuronal function awaits detailed study and definitive answers.

\section{Mark W Sonderup}

Department of Medicine, Division of Hepatology and Lennox Eales Porphyria Labs, University of Cape Town, Faculty of Health Sciences and Groote Schuur Hospital, Cape Town, South Africa msonderup@samedical.co.za

\section{Richard J Hift}

School of Clinical Medicine, University of KwaZulu-Natal, Durban, South Africa

Corresponding author: MW Sonderup (msonderup@samedical.co.za)

1. Anderson KE, Sassa S, Bishop DF, Desnick RJ. Disorders of heme biosynthesis: X-linked sideroblastic anemias and the porphyrias. In: Scriver CR, Beaudet AL, Sly WS, et al., eds. The Metabolic an Pischik E, Kauppinen R. Neurological manifestations of acute intermittent porphyria. Cell Mol Biol (Noisy-le-grand) 2009;55(1):72-83

3. Simon NG, Herkes GK. The neurologic manifestations of the acute porphyrias. J Clin Neurosci 2011;18(9):1147-1153. [http://dx.doi.org/10.1016/j.jocn.2011.01.003]

4. Lin CS, Park SB, Krishnan AV. Porphyric neuropathy. Handb Clin Neurol 2013;115:613-627. [http:// dx.doi.org/10.1016/B978-0-444-52902-2.00036-9

5. Ni J, Zhou LX, Hao HL, et al. The clinical and radiological spectrum of posterior reversible encephalopathy syndrome: A retrospective series of 24 patients. I Neuroimaging 2011;21(3):219-224 [http://dx.doi.org/10.1111/j.1552-6569.2010.00497 x]

6. Hift RJ, Meissner PN. An analysis of 112 acute porphyric attacks in Cape Town, South Africa: Evidence that acute intermittent porphyria and variegate porphyria differ in susceptibility and severity. Medicine 2005;84(1):48-60. [http://dx.doi.org/10.1097/01.md.0000152454.56435 f3]

7. Anderson KE, Bloomer JR, Bonkoysky $\mathrm{HL}$, et al. Recommendations for the diagnosis and treatment of the acute porphyrias. Ann Intern Med 2005;142(6):439-450. [http://dx.doi.org/10.7326/0003-4819142-6-200503150-00010]

8. Barraza $G$ Serranova T Herrero $C$, et al. Brainstem dysfunction in variegate porphyria. Muscle Nerve 2012;46(3):426-433. [http://dx.doi org/10.1002/mus 23367]

9. Mullin S. Phats $A$, to an , Plats A, Randhawa K, Watts P. Cerebral vasospasm and anterior circulation stroke secondary org/10.1136/practneurol-2012-000288]

10. Kumar B Acte inter Psychosomatics 2012:53(5):494-498. [http://dx.doi.org/10.1016/j psym-2012.03 008]

11. Mer UA Schures . Meyer UA, Schuurmans MM, Lindberg RL. Acute porphyrias: Pathogenesis of neur

12. King PH, Petersen NE, Rakhra R, Schreiber WE. Porphyria presenting with bilateral radial motor

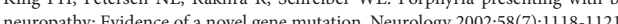

neuropathy: Evidence of a novel gene mutation. Neurology 202,58(7).118-1121. Pharmacol 1975;24(2):99-301.

4. Kauppinen R. Porphyrias. Lancet 2005:365(9455).241-252 [http://dx.doi.org/10.1016/S0140-

5. Seth AK, Badminton MN, Mirza D, Russell S, Elias E. Liver transplantation for porphyria: Who, when, and how? Liver Transpl 2007;13(9):1219-1227. [http://dx.doi.org/10.1002/lt.21261]

Albertyn CH, Sonderup M, Bryer A, Corrigall A, Meissner P, Heckmann JM. Acute intermitten porphyria presenting as progressive muscular atrophy in a young black man. S Afr Med 2014;104(4):283-285. [http://dx.doi.org/10.7196/SAMJ.778

7. Meissner PN, Dailey TA, Hift RJ, et al. A R59W mutation in human protoporphyrinogen oxidase results in decreased enzyme activity and is prevalent in South Africans with variegate porphyria. Nat
Genet 1996;13(1):95-97. [http://dx.doi.org/10.1038/ng0596-95]

S Afr Med J 2014;104(4):285-286. DOI:10.7196/SAMJ.7782 